\title{
Management of lateral vibration serviceability of temporary grandstand and human health risk assessment based on experiment
}

\author{
Lin $\mathrm{He}^{\mathrm{a}, \mathrm{b}}$, Jian Yuan, ${ }^{\mathrm{a}, \mathrm{b}}$, Feng Fan ${ }^{\mathrm{a}, \mathrm{b}}$, Cong Liu ${ }^{\mathrm{a}, \mathrm{b}}$ \\ ${ }^{a}$ Key Lab of Structures Dynamic Behavior and Control of Ministry of Education (Harbin Institute of Technology), \\ Harbin, 150090, China; \\ ${ }^{\mathrm{b} S c h o o l}$ of Civil Engineering, Harbin Institute of Technology, 73 Huang he Street, Nan Gang District, Harbin, \\ 150090, China.
}

\begin{abstract}
Excessive vibration of temporary grandstand owing to crowd has lateral rhythmic motions can cause human in panic, which attracted increasing attention in recent years. This paper focuses on experiments that a temporary grandstand occupied 20 participants is oscillated by a shaking table with a series of random waves and induced by crowd with rhythmic swaying motions at lateral direction, respectively. And then a series of vibration perception questionnaires about crowd reaction are obtained. Evaluation of annoying level derives in concept of degree of membership and annoying rate method is proposed, then the human health risk of vibration serviceability of temporary grandstand is assessed with acceleration vibration dose value(VDV). From these results it is clear that standing crowd is more tolerant to vibration than seated crowd. The measured vibrations generated by crowd activities on temporary grandstand can cause panic in crowd. New relationship between the annoyance rate and structural acceleration VDV at logarithmic coordinate is proposed. The findings of this study can be utilized to manage the vibration of temporary grandstand and assess the human health risk.
\end{abstract}

Keywords: temporary grandstand; lateral vibration experiment; vibration dose value; annoyance rate; human health risk

\section{Introduction}

The problems of vibration serviceability of structure such as in long-span floor structures[1], footbridges[2] and grandstands[3,4] which can gather large crowd have become more prevalent in recent years. It is different in the safety of structure due to the failure of structural component; excessive vibration of structure can cause crowd discomfort or panic. Serviceability of grandstand relates to the comfort of spectators, and human perception is of primary importance with any tendency to panic or feeling of discomfort being related to the dynamic response of the structure[5]. This seems to be a common problem in temporary demountable grandstands (TDGs), which lightweight structural components of TDG can be rapidly assembled, easily dismantled and reused that result in low stiffness of structure at lateral direction, it can be susceptible to vibrations that caused by active crowds.

It is a fact that human can feel the vibration from structure, but the degree of perception for structural vibration cannot be measured with any direction assessment methods or instruments. Studying the relationship between human perception and spur belongs to the branch of psychophysics subject. Vibration environments, in terms of human sensation of vibration levels, need to be quantified by psychological research. And introspection is used to describe an experimental technique that was first developed by psychologist Wilhelm Wundt. In Wundt's lab, there were two key components that make up the contents of the human mind: sensations and feelings, and Wundt believed that researchers needed to do more than simply identify the structure or elements of the mind. Instead, it was essential to look at the processes and activities that occur as people experience the world around them[6]. Therefore, it is necessary to conduct a psychophysical experiment survey by means of a category judgment method[7]. Although evaluation and assessment of vibration serviceability is a complicate task, it is a reasonable and available method that using experimental introspection with questionnaire to evaluate the reaction of human perception. So from the early years such as in 1931 Reiher and Mesiter with a shaking platform[8], to 1971 Khan and Parmelee using a rotating display table[9], 1972 Chen and Robertson experiment at a wheeled windowless test room[10] and 1974 Wiss and Parmelee put human at a rise floor[11], they used this method to investigate the vibration serviceability of structure. 
A number of research projects have, to date, largely focused on producing load models to accurately represent the dynamic crowd load and the human-structure interaction, however, whilst the vibration response of grandstand structure is becoming better understood, the question arises as to what level of dynamic response is acceptable to the users[12]. There have been few findings on the subject of serviceability of grandstands, for example Kasperski has carried out full scale test on one bay of a permanent cantilevered stand[3]; Browning determined the key factors of influencing human perception and acceptability of vibrations in permanent grandstands, which induced by synchronized crowd loading with 17 persons[12]. Meanwhile, a resemblance grandstand occupied 15 spectators that attached to a motion simulator located on each corner to investigate human vibration perception and comfort states[13]. In particular, Setareh proposed new relationships between the current vibration evaluation parameters along with guidance for the assessment of human exposure to vibration owing to rhythmic activities[4]. What these reviews have highlighted is that vibrations were induced by vertical excitation and no research analyzed the human vibration perception in the TDG. And what's more, lateral vibration is more likely to be induced than vertical vibration would happen in reality for TDG[14]. This remains an open problem in the area, the aim here is to investigate the vibration serviceability of TDG.

So with this aim in mind, in this paper we present a new experiment to determine the human horizontal vibrations perception at a TDG occupied 20 persons with vibration questionnaires, which vibrations derived in a shaking table and crowd motions, respectively. Based on these experimental results, the vibration acceptability of the TDG is investigated by a annoyance rate method that the fuzzy logic method and the probability theory was combined with the signal detecting theory of psychophysics[15-17]. As alluded to earlier, this method has been available for appraising the vibration comfort of vehicle suspension system[18,19], high-speed train[20], pedestrian bridge[21], floor structure[22,23], and noise annoyance[24,25].

The next section presents the lateral oscillation experiment in this study. In Section 2, the evaluation method is introduced and the relationships of evaluation parameters of structural vibration are analyzed. New relationship between annoyance rate and structural acceleration VDV is proposed, and the main findings and discussions are outlined in Section 3. The conclusions will be presented in the final chapter..

\section{Lateral vibration experiments of temporary grandstand}

For simulating the lateral vibration of temporary grandstand, a series of random waves were chose as external excitation when temporary grandstand occupied crowd on a shaking table, and to investigate the passive crowd annoying levels of vibration. Besides, human induced vibration derived in the active crowd when they have rhythmic movements on temporary grandstand, which as internal excitation experiments to investigate the passive and/or active crowd annoying levels of vibration. Both of the two experiments are implemented in this paper.

\subsection{Test condition}

To better obtain the vibration perception of crowd who occupied at temporary grandstand, a temporary demountable grandstand rig was constructed at the Key Lab of Structures, Dynamic Behavior and Control of the Ministry of Education at the Harbin Institute of Technology. Table 1 depicts the members of test TDG, its weight and structural schematic. The structure is comprised of nine kinds of members, which shown in schematic. There are four rows and five columns seats that accommodating 20 persons. Seating system includes guardrails, seat braces, seat beams and decks and stepped frames. Hollow bar of supporting system includes standards, ledgers, bay bracings and base jacks. The type of connection employed to assembly the hollow bars is plug-pin joint, which is shown in Table 1, and the deck laps on the seat braces and triangular stepped frame. The weight of empty structure is $912.98 \mathrm{~kg}$.

In Fig.1, the main dimensions of a structure are: height of front row $(2.6 \mathrm{~m})$, back $(4.0 \mathrm{~m})$, left-to-right span ( $2.5 \mathrm{~m})$ and front-to-back span (up to $3.0 \mathrm{~m}$ ). Four accelerometer points A1-A4 installed at each row which stands for the responses of structural seating system is considered as the crowd vibration perception from the structure. Also there are three linear variable differential transformers (L1-L3) are shown in this Figure. Data were collected at a sampling frequency of $1 \mathrm{kHz}$ using IMC data acquisition software carrying a built-in anti-alias filter (German model IMC CRONOS compact-400-08 with robust housing) and a DH5922 (Dong Hua, China). The recorded 
curves were digitally filtered with a frequency content of up to $25 \mathrm{~Hz}$ in order to minimize the effect of background noise.

\begin{tabular}{|c|c|c|c|c|}
\hline TDG & Kinds of Member & $\operatorname{Mass}(\mathrm{kg})$ & Schematic of Structure & Plug-pin joint \\
\hline \multirow{5}{*}{$\begin{array}{l}\text { Seating } \\
\text { system }\end{array}$} & (1)Guardrail(include & 234.80 & & \\
\hline & (2) Seat brace & 80.46 & & \\
\hline & (3)Seat beam & 114.45 & & \\
\hline & (4)Deck & 120.00 & & \\
\hline & $\begin{array}{l}\text { (5)Triangular } \\
\text { stepped frame }\end{array}$ & 92.80 & & \\
\hline \multirow{5}{*}{$\begin{array}{c}\text { Hollow } \\
\text { bar of } \\
\text { supporting } \\
\text { system }\end{array}$} & (6) Standard & 66.68 & & \\
\hline & (7)Ledger & 113.75 & & \\
\hline & (8)Bay bracing & 69.04 & & \\
\hline & (9)Base Jack & 21.00 & & \\
\hline & $\begin{array}{l}\text { (10)Vibration table } \\
\text { Total }\end{array}$ & $\begin{array}{c}/ \\
912.98\end{array}$ & & \\
\hline
\end{tabular}

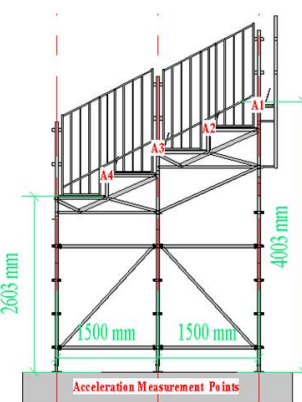

a) structural elevation

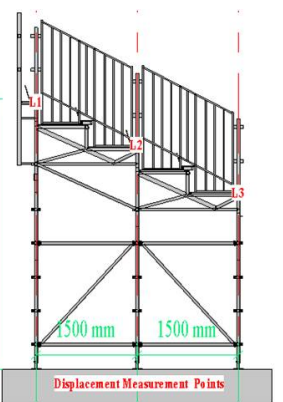

b) external excitation

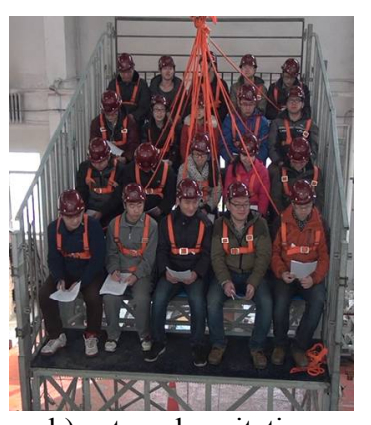

test structure

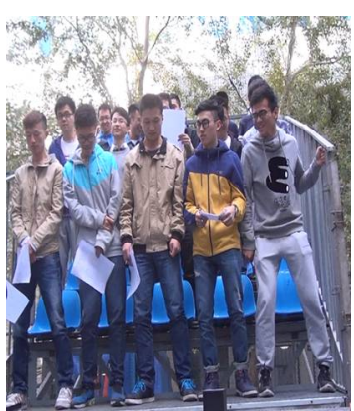

c) human excitation

Interestingly BS6841[26] indicated that live subjects rather than representative masses or dummies should be used for measuring vibrations on non-rigid surfaces. Whilst, it also noted that here are various factors influencing human response to vibrations, such as age, sex, fitness, experience, expectation, motivation, posture etc that is intrinsic variables. So, in terms of this there are forty volunteers that generally made up of volunteers from the university and society to consider as much variety as possible. The participants are typically male and female, between 20-35 years old and have a health body to participate in the test. Fig 2 shows a unique reference number was allotted to each participant so that their position on the structure could be logged, and the weight of each participant was also measured, the gross weight of the twenty participants is $1405.7 \mathrm{~kg}$ and $1338.7 \mathrm{~kg}$ respectively. All participants are not specialized training for perceive the vibration, and no specific posture was prescribed and participants sat or stand freely. Because it is a psychophysical experiment or survey by means of a category judgment method, this requires participants to rate their perception and/or comfort of the magnitude of the vibrations. Base on their perception, everyone filled in the questionnaire (See Fig 3) for rating the vibration that had been experienced during the lateral vibration tests when they seating and/or standing, respectively.

For external excitation experiment, three kinds of seismic waves: Chi Chi (1999s), El Centro (1940s) and Kobe waves (1995s), including two lateral directions, West-East (W-E) and North-South $(\mathrm{N}-\mathrm{S})$ were chose as horizontal stochastic force to the test rig. The peak acceleration of these seismic waves between $0.16 \mathrm{~ms}^{-2}$ to $1.54 \mathrm{~ms}^{-2}$ with 53 force testing sessions in total(see Table 2). For example, there are nine test curves of Chi Chi(W-E) from the peak acceleration 18.29 gal to 91.45 increasing 0.5 times, i.e: 18.29 gal, $27.43 \operatorname{gal}(18.29 \times 1.5)$, $36.58 \mathrm{gal}(18.29 \times 2)$, 45.73gal(18.29×2.5), $\quad 54.87 \operatorname{gal}(18.29 \times 3), \quad 64.02 \operatorname{gal}(18.29 \times 3.5), \quad 73.16 \operatorname{gal}(18.29 \times 4)$, 82.31gal $(18.29 \times 4.5)$, 91.45gal $(18.29 \times 5.5)$, other kinds of test curves are the same increasing method. 


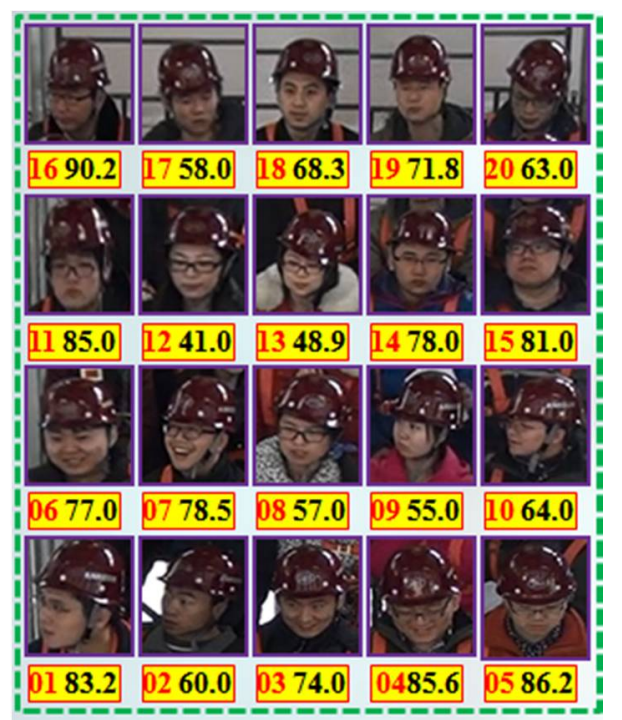

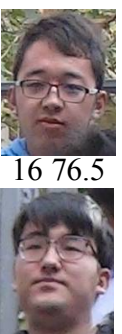


0159.3

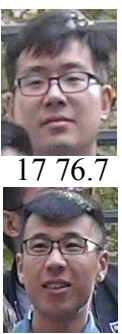

1260.6

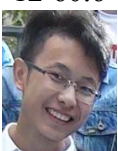

0758.4

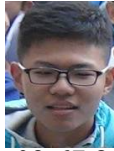

0267.8

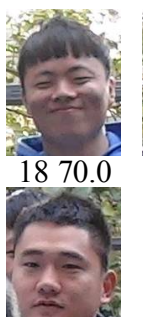

1388.0

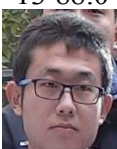

0870.3

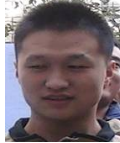

$0 3 \longdiv { 7 3 . 2 }$
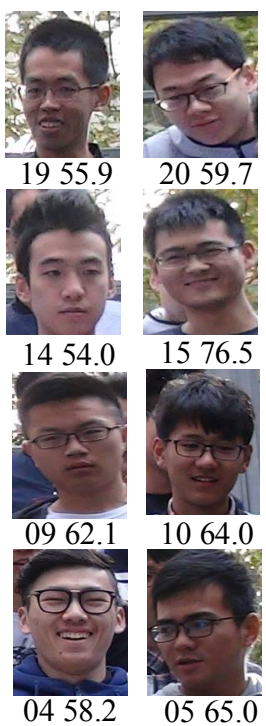

Fig.2 The participants of TDG vibration test Table 2. Details of test seismic waves

\begin{tabular}{ccccc}
\hline \multicolumn{2}{c}{ Random wave } & $\begin{array}{c}\text { Peak acceleration } \\
(\text { gal })\end{array}$ & $\begin{array}{c}\text { Duratio } \\
\mathrm{n}(\mathrm{s})\end{array}$ & Number \\
\hline Chi Chi & W-E & $18.29-91.45$ & 48 & 9 \\
$(1999 \mathrm{~s})$ & $\mathrm{N}-\mathrm{S}$ & $16.26-89.43$ & 46 & 10 \\
\cline { 2 - 5 } El Centro & $\mathrm{W}-\mathrm{E}$ & $21.48-96.66$ & 40 & 8 \\
$(1940 \mathrm{~s})$ & $\mathrm{N}-\mathrm{S}$ & $31.29-140.81$ & 40 & 8 \\
Kobe & $\mathrm{W}-\mathrm{E}$ & $30.78-153.90$ & 30 & 9 \\
$(1995 \mathrm{~s})$ & $\mathrm{N}-\mathrm{S}$ & $30.57-152.85$ & 40 & 9 \\
\hline
\end{tabular}

For internal excitation, there are eleven experiment conditions that crowd has swaying activities at temporary grandstand, the detail of swaying person's number, test conditions and excitation swaying frequencies are shown in the Table 3. For the first and second condition twenty persons finished nine frequencies swaying movements, some of them finished six frequencies swaying movements in the rest conditions

Table 3 Details of crowd rhythmic activities

\begin{tabular}{|c|c|c|}
\hline Test condition number & Test conditions & Excitation swaying frequency $(\mathrm{Hz})$ \\
\hline 1 & All standing persons swaying & $0.5,0.75,1.0,1.1,1.25,1.4,1.5,1.7,1.8$ \\
\hline 2 & All seated persons swaying & $0.5,0.75,1.0,1.1,1.25,1.4,1.5,1.7,1.8$ \\
\hline 3 & $\begin{array}{l}\text { Number } 6-20 \text { person standing } \\
\text { swaying, } 1-5 \text { person seated }\end{array}$ & $0.5,0.75,1.0,1.1,1.25,1.4$ \\
\hline 4 & $\begin{array}{l}\text { Number } 11-20 \text { person standing } \\
\text { swaying, } 1-10 \text { person seated }\end{array}$ & $0.5,0.75,1.0,1.1,1.25,1.4$ \\
\hline 5 & $\begin{array}{l}\text { Number } 16-20 \text { person standing } \\
\text { swaying, } 1-15 \text { person seated }\end{array}$ & $0.5,0.75,1.0,1.1,1.25,1.4$ \\
\hline 6 & $\begin{array}{l}\text { Number 6-20 person standing } \\
\text { swaying, } 1-5 \text { person standing }\end{array}$ & $0.5,0.75,1.0,1.1,1.25,1.4$ \\
\hline 7 & $\begin{array}{l}\text { Number } 11-20 \text { person standing } \\
\text { swaying, } 1-10 \text { person standing }\end{array}$ & $0.5,0.75,1.0,1.1,1.25,1.4$ \\
\hline 8 & $\begin{array}{l}\text { Number } 16-20 \text { person standing } \\
\text { swaying, } 1-15 \text { person standing }\end{array}$ & $0.5,0.75,1.0,1.1,1.25,1.4$ \\
\hline 9 & $\begin{array}{l}\text { Number } 6-20 \text { person seated } \\
\text { swaying, } 1-5 \text { person seated }\end{array}$ & $0.5,0.75,1.0,1.1,1.25,1.4$ \\
\hline 10 & $\begin{array}{l}\text { Number } 11-20 \text { person seated } \\
\text { swaying, } 1-10 \text { person seated }\end{array}$ & $0.5,0.75,1.0,1.1,1.25,1.4$ \\
\hline 11 & $\begin{array}{l}\text { Number } 16-20 \text { person seated } \\
\text { swaying, } 1-15 \text { person seated }\end{array}$ & $0.5,0.75,1.0,1.1,1.25,1.4$ \\
\hline
\end{tabular}

\subsection{Vibration perception questionnaire}

As mentioned previously, no standards or codes can provide specific clause on the assessment of human vibration acceptability for TDG, even not to mention the lateral vibration comfort. But, a series of classic experiments about human perception that participants rate their feeling of the vibration were carried out $[3,8,9,12,13]$. All these researchers classed the human 
perception and vibration level three to six categories, which based on the concept of equidistance followed human psychological changes. Some achievements have been adopted by BS6472-1[27] and ISO2631-1[28] standards. So, according to these findings, the level of vibration perception (Six categories) and comfort are provided with vibration perception questionnaires, which require participants to select their subjective perception and/or levels of comfort during exposure to vibration are used in this paper. The questionnaires contain the level of vibration perception with the level comfort and shows in the Table 4, and the Fig.3 displays these questionnaires were finished by forty participants.

Table 4 Human perception and comfort category

\begin{tabular}{ccc}
\hline Ordinal & Perception Category & Subjective Response \\
\hline 1 & Imperceptible & No response(Nice) \\
2 & Litter Perception & Normal(Comfortable) \\
3 & Clear Perception & Accept(Slightly Uncomfortable) \\
4 & Little Strong Perception & Litter nervous(Uncomfortable) \\
5 & Strong Perception & Nervous(Very Uncomfortable) \\
6 & Very Strong Vibration & Panic(Extreme Uncomfortable) \\
\hline
\end{tabular}

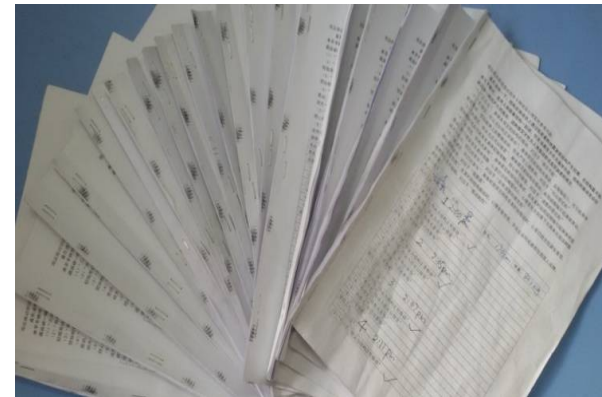

a) external excitation experiment

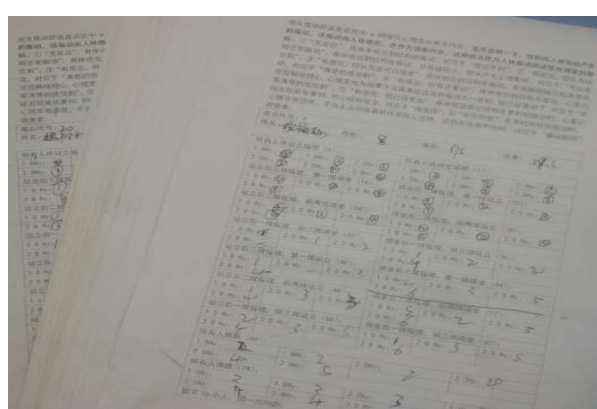

b) crowd induced vibration

Fig.3 Participant finished questionnaires

\section{Evaluation method}

According to record the human sensation of vibration levels from participant's perception and comfort, the basic evaluation methods for measuring vibration is calculated using three forms of acceleration: peak acceleration limits(was cited in NBCC[29]); acceleration root mean square (RMS) of weighted frequency; vibration dose value (VDV). The latter two are acceptable by most standards (BS7085[30], BS6472[31] and ISO10137[32]) to quantify vibration levels. They are calculated by the Eq.(1), and $a(t)$ is a measured acceleration of structure.

$$
\begin{gathered}
a_{w}(t)=W(f) \cdot a(t) \\
a_{w p}=\max \left|a_{w}(t)\right| \\
a_{w r m s}=\left[\int_{0}^{T} a_{w}^{2}(t) d t\right]^{2} \\
a_{V D V}=\left[\int_{0}^{T} a_{w}^{4}(t) \mathrm{d} t\right]^{0.25}=\left(\lim _{\lambda \rightarrow 0} \sum_{i=1}^{n} a_{w}^{4}\left(\zeta_{i}\right) \cdot \Delta t_{i}\right)^{0.25}=\left(\sum_{i=1}^{n}\left[W(f) a\left(t_{i}\right)\right]^{4} \cdot f^{\prime}\right)^{0.25}, \lambda=\max \left\{\Delta x_{1}, \Delta x_{2}, \cdots, \Delta x_{n}\right\}
\end{gathered}
$$

With $a_{w}(t)=$ frequency weighted acceleration in $\mathrm{ms}^{-2}$;

$W(f)=$ frequency-weighting function from ISO2631-1[28], and $f$ is the structural natural frequency;

$$
\begin{aligned}
a_{w p}(t) & =\text { frequency weighted peak value of acceleration in } \mathrm{ms}^{-2} ; \\
a_{w r m s}(t) & =\text { frequency weighted peak value of acceleration in } \mathrm{ms}^{-2} ; \\
a_{w v d v}(t) & =\text { frequency weighted peak value of acceleration in } \mathrm{ms}^{-1.75} ; \\
f^{\prime} & =\text { Sample frequency in s; } \\
T & =\text { vibration duration in s. }
\end{aligned}
$$

For calculating the frequency weight function $W(f)$, the structural natural frequency needs to be obtained. So a rope was tied at the top of structural guardrail and pull it when rope tightened, 
then suddenly releasing it. So the filtered free decaying vibration curves can be obtained, and shown in Fig.4. There have two free decaying tests, the left figure shown four curves which stand for four test points at each rows(see Fig.1), and the middle figure is the part of their average curve(time from 8 second to end). The right figure shows the corresponding frequency domain analysis, it revealing there is only a significant dominant frequency, neglecting several tiny peak frequencies at the tail of the curve. So the frequency $2.499 \mathrm{~Hz}$ is assumed as structural damped natural frequency, and according to the curve of frequency weight from ISO2631-1[28], $W(f)=0.74$.
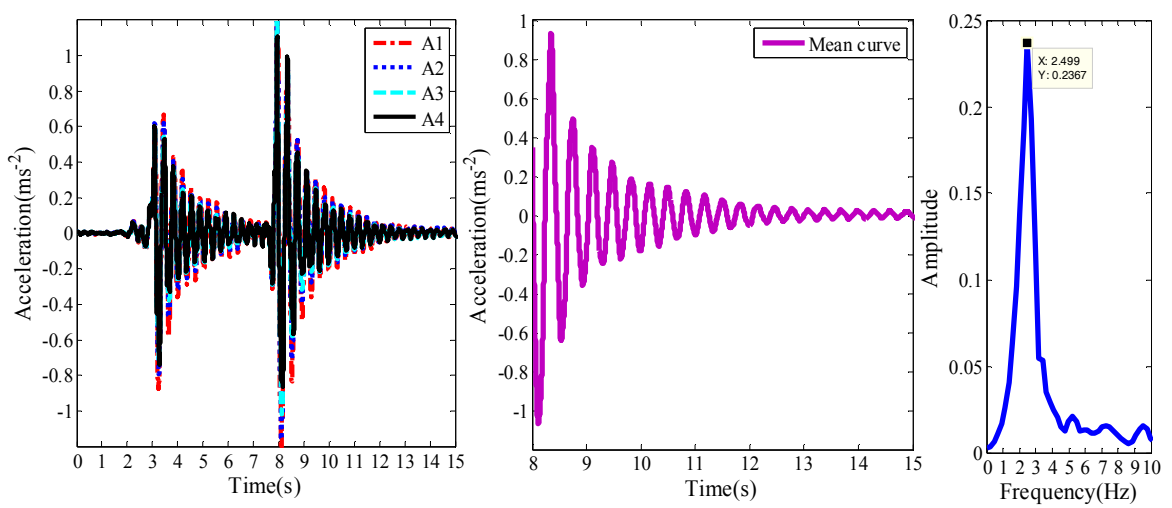

Fig.4 The measured points of time history and frequency domain analysis from free decaying vibration

\subsection{Annoyance rate method}

Although the limit acceleration value was given in some standards like ISO2631-1[28], the membership between the limit value and comfortable level was not reasonable extrapolated. The result of questionnaires includes the ambiguity of seismesthesia and the sensitivity randomness existing in participants' response to vibration environment. All these uncertainties need to be analyzed from a view psychophysics. So firstly the seismesthesia of membership function and corresponding conditional probability distribution[14] is calculated by Eq.(2) based on the Table 4 and questionnaires.

$$
v_{j}=\frac{j-1}{K-1}, j=1,2, \ldots, K
$$

With $v_{j}=$ the seismesthesia of membership value of the $j$ th type of the unacceptable range;

$K=$ the class number of the subjective response, according to Table $4, K=6$;

So the subjective response corresponding to the value of $v_{j}$ can be shown in the Table 5 .

\begin{tabular}{lc}
\multicolumn{2}{c}{ Table 5 Seismesthesia membership values } \\
\hline Subjective response & Membership value \\
\hline$j=1$ Noresponse & 0 \\
$j=2$ Normal vibration & 0.2 \\
$j=3$ Acceptable & 0.4 \\
$j=4$ A little unacceptable & 0.6 \\
$j=5$ Scary & 0.8 \\
$j=6$ Panic & 1.0 \\
\hline
\end{tabular}

Secondly, a new evaluation index annoyance rate method that is a fuzzy stochastic model for participant response to vibrations is presented. The method considers these uncertainties with the fuzzy logic method and the probability theory, combined the objective experimental data statistics. So, annoyance rate is the proportion of some kind of subjective response under certain external stimulus intensity, which considers synthetically response ambiguity and randomness with fuzzy membership value. It is useful as a benchmark to determine the annoyance threshold for vibration serviceability criteria, that threshold indicates the ration of people who cannot accept the vibration to the statistical that total number. Under discrete distribution, the annoyance rate can be calculated by Eq.(3): 


$$
R(x=i)=\frac{\sum_{j=1}^{K} v_{i j} n_{i j}}{\sum_{j=1}^{K} n_{i j}}
$$

With $R(x=i)=$ Annoyance rate of the $i$ th vibration intensity;

$v_{i j}=$ the membership of value is calculated by Eq. (1) at the $i$ th vibration intensity; $n_{i j}=$ the number of subjective response of the $j$ th type of the $i$ th vibration intensity $K=$ The class number of the subjective response, $K=6$ (see Table 5)

\subsection{Relationship of structural vibration evaluation parameters}

For shaking table experiment results, just as Fig.5 shows the four accelerometers points A1-A4 of structure and shaking table acceleration A0 recorded curves respectively. According to Eq.(1), the peak value, RMS and VDV of structural acceleration can be obtained. And the peak value of table acceleration against three forms of structural acceleration is shown in Fig.6. Hollow dots stand for peak values, square dots stand for RMS values and diamond dots stand for VDV values. Three quadratic polynomial formulas are used for fitting these dots and calculated by Eq.(4). It should be noted that the fitting curve of VDV is lower than the other two, and the fitting curve of RMS is higher than the other two.

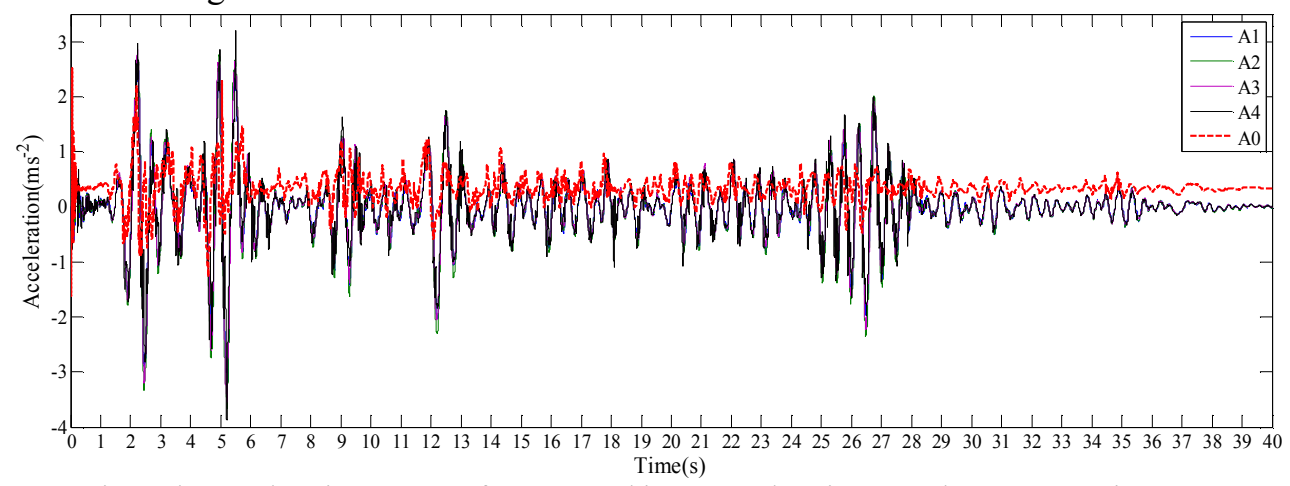

Fig. 5 The acceleration curves of A1-A4 and input acceleration A0 when structure is empty

$$
\begin{aligned}
& a_{w p}=-0.7081 a_{i n p}^{2}+2.3490 a_{i n p}-0.0627 \\
& a_{w r m s}=-1.245 a_{i n p}^{2}+3.435 a_{i n p}-0.177 \\
& a_{w v d v}=-0.6883 a_{i n p}^{2}+2.1240 a_{i n p}-0.1143
\end{aligned}
$$

With $a_{i n p}=$ the peak value of acceleration of shaking table in $\mathrm{ms}^{-2}$;

$a_{w p}=$ the frequency weighting of structural acceleration peak value in $\mathrm{ms}^{-2}$;

$a_{w r m s}=$ the frequency weighting of structural acceleration RMS value in $\mathrm{ms}^{-2}$;

$a_{w v d v}=$ the frequency weighting of structural acceleration VDV value in $\mathrm{ms}^{-1.75}$; 


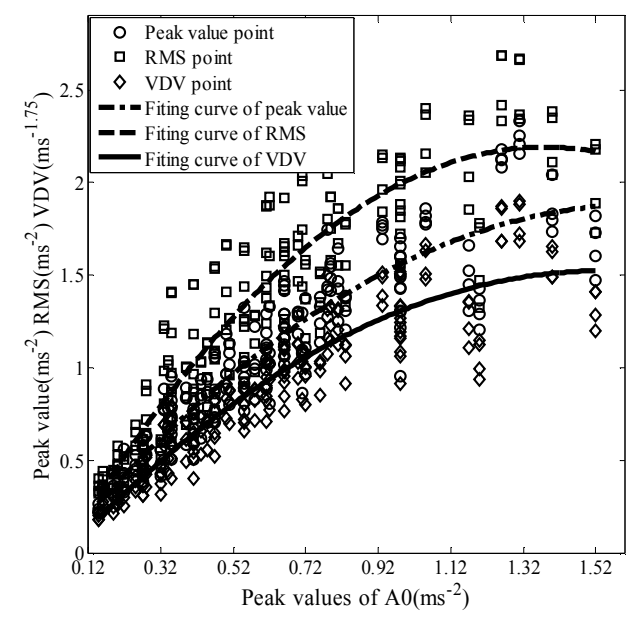

Fig.6 The relationship of input accelerations and output accelerations: peak values, RMS values and VDV values

The standard BS6472-1[27] and ISO2631-1[28] has given an approximate relationship between VDV and RMS when vibrations are statistically stationary, and Griffin[33] introduced the crest factor, $C_{\mathrm{F}}=\frac{a_{w p}}{a_{w r m s}}$ when it less than 6 , the VDV can be estimated(eVDV) using $a_{w r m s}$ which as shown in Eq.(5). However, as can be seen in Fig.4, it is not applicable to the vibrations recorded in this experiment as the calculated $C_{\mathrm{F}}$ are significantly smaller than 6 . Ellis with Littler[34] has given the relationship between VDV and peak value, just as shown in Eq.(6), whereas it is also not applicable to this experiment results.

$$
\begin{gathered}
e a_{w v d v}=\sqrt[4]{\left(1.40 a_{w r m s}\right)^{4} T} \\
a_{w v d v}=1.35 a_{w p}
\end{gathered}
$$

Besides, the crest factor $C_{\mathrm{F}}$ against $\frac{a_{w v d v}}{a_{w p}}$ is analyzed and shown in Fig.7, it is fitted by a linear curve with Eq.(7), and that different from Setareh[4] given a second-order relationship, maybe due to Setareh researched excitations and structures are different in this paper.

$$
\frac{a_{w v d v}}{a_{w p}}=-0.5682 C_{\mathrm{F}}+1.2780
$$

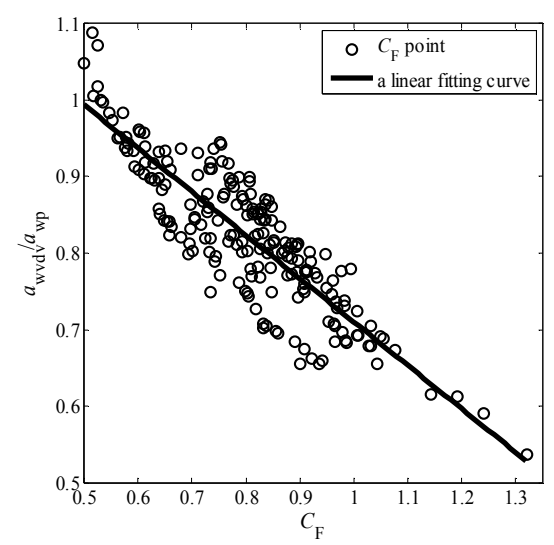

Fig. $7 a_{\mathrm{wvdv}} / a_{\mathrm{wp}}$ plotted against $C_{\mathrm{F}}$ for measured data from shaking table tests

So, based on the computed $a_{w p}, a_{w r m s}$ and $a_{w v d v}$, Fig.8 shows the scatter plots of $a_{w p}$, $a_{w r m s}$ plotted against $a_{w v d v}$, and the curve fit based on the following a linear relationship with Eq.(8). The fitting degree is 0.95 and 0.94 respectively, which indicated that there existed a good linear relationship between of each other.

$$
\begin{gathered}
a_{w v d v}=0.82760 a_{w p}-0.00154 \\
a_{w v d v}=0.6442 a_{w r m s}+0.0022
\end{gathered}
$$





Fig. $8 a_{\mathrm{wvdv}}$ plotted against $a_{\mathrm{wp}}$ and $a_{\mathrm{wrms}}$ from shaking table measured data

For human induced vibration experiment, the excitations derived from crowd with rhythmic activities, which different from the shaking table with seismic waves. For example, Fig.9(a) shows one of the time history of structural acceleration which was oscillated by twenty persons when they have rhythmic movements. Then the acceleration peak values, RMS and VDV of each test condition(Table 3) result are calculated, and the scatter plots the three measures plotted against crowd swaying frequencies is shown in Fig.9(b). In this Figure, also the hollow dots stand for peak values, square dots stand for RMS values and diamond dots stand for VDV values. It is found that when crowd swaying frequency is larger than $1.3 \mathrm{~Hz}$, the VDV into a significant increase and higher than RMS and peak value, just only the crowd swaying frequency is lower than $1.3 \mathrm{~Hz}$, the RMS is larger than peak value and peak value is larger than VDV. The reason maybe crowd have $1.3 \mathrm{~Hz}$ or more higher frequencies activities which induced more than $1 \mathrm{~ms}^{-2}$ of acceleration curve during time is longer than other lower swaying frequencies activities, just as Fig.9a) shows most of the time the peak values are larger than $1 \mathrm{~ms}^{-2}$.

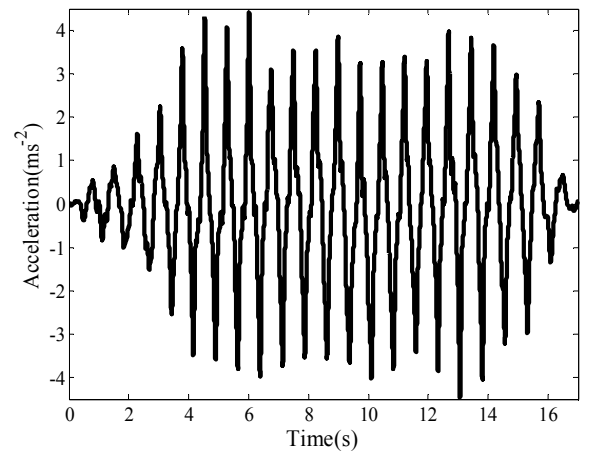

(a) Structural acceleration curve of seated crowd with $1.6 \mathrm{~Hz}$ swaying

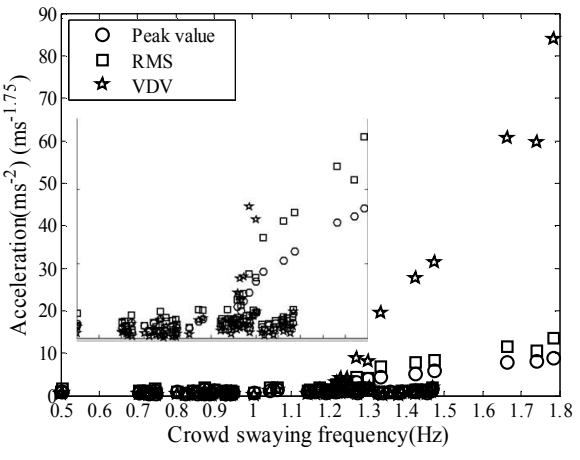

(b) Three measures acceleration against crowd swaying frequencies

Fig.9 The structural acceleration peak value、RMS and VDV relationship with crowd swaying frequencies

The crest factor $C_{\mathrm{F}}$ values also are smaller than 6 , and $C_{\mathrm{F}}$ against $\frac{a_{w v d v}}{a_{w p}}$ is also shown in Fig.10. It is obviously no relationship between them, not only twenty person have rhythmic swaying movements(Fig.10(a)) but also some persons have rhythmic swaying(Fig.10(b)). Compare with the shaking table experiment that excitation were exported with a linear increasing, crowd induced structure vibration has a certain randomness due to the output energy of their body are uncertain.
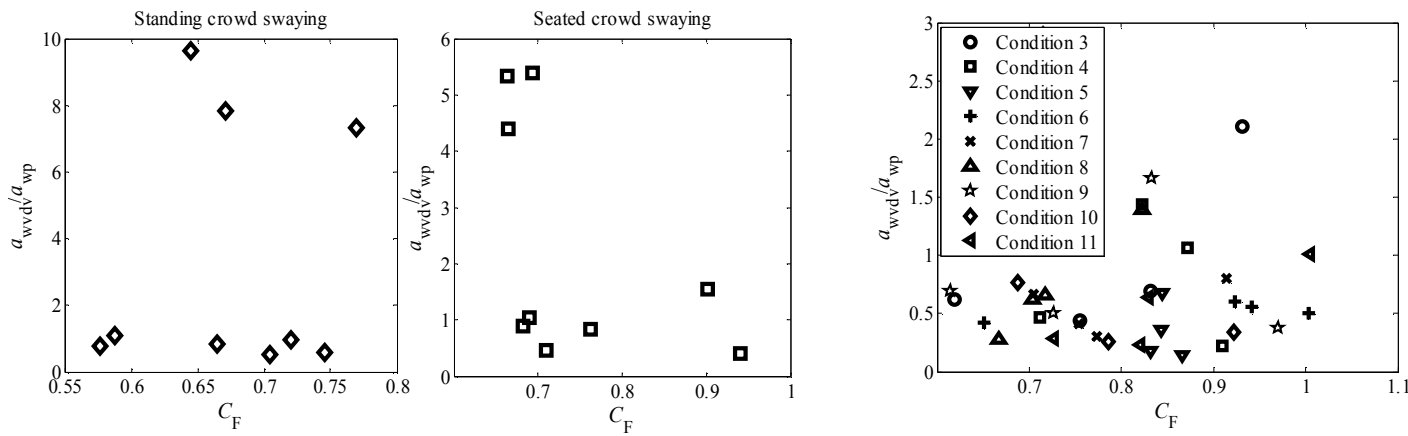
(a) Twenty persons swaying

(b) Test conditions 3-11

Fig. $10 a_{\text {wvdv }} / a_{\text {wp }}$ plotted against $C_{\mathrm{F}}$ for measured data from human tests

When the scatter $a_{w p}, a_{w r m s}$ plotted against $a_{w v d v}$ respectively, as shown in Fig.11(a), both of them have a nonlinear relationship with $a_{w v d v}$. When changed Cartesian coordinate system into Logarithmic coordinate system, it is found that there is a linear relationship between $a_{w p}, a_{w r m s}$ and $a_{w v d v}$, respectively(Fig.11(b)). And the fitting curve is Eq.(9):

$$
\begin{gathered}
\log _{10}\left(a_{w v d v}\right)=2.0793 \log _{10}\left(a_{w p}\right)-0.1447 \\
a_{w p}=10^{0.0696} \cdot a_{w v d v}^{\frac{1}{2.0793}} \\
\log _{10}\left(a_{w v d v}\right)=2.01935 \log _{10}\left(a_{w r m s}\right)-0.36290 \\
a_{w r m s}=10^{0.17970} \cdot a_{w v d v}^{\frac{1}{2.01935}}
\end{gathered}
$$
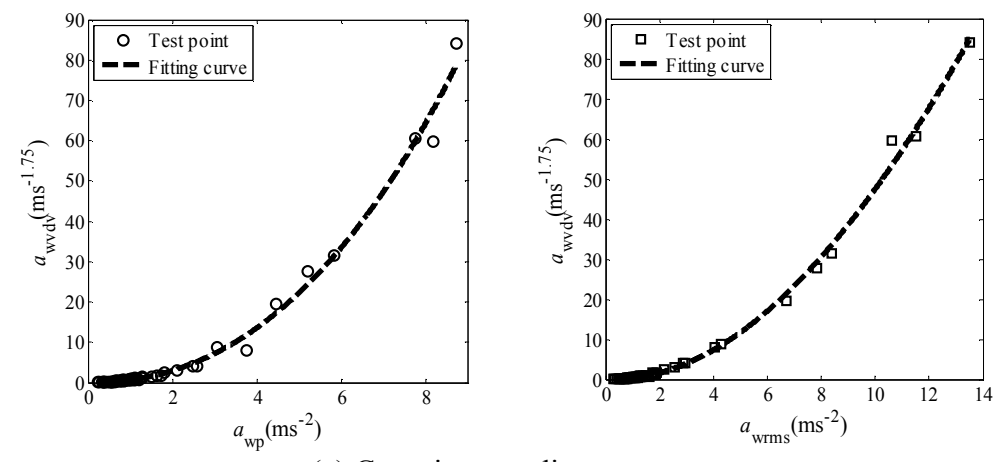

(a) Cartesian coordinate system
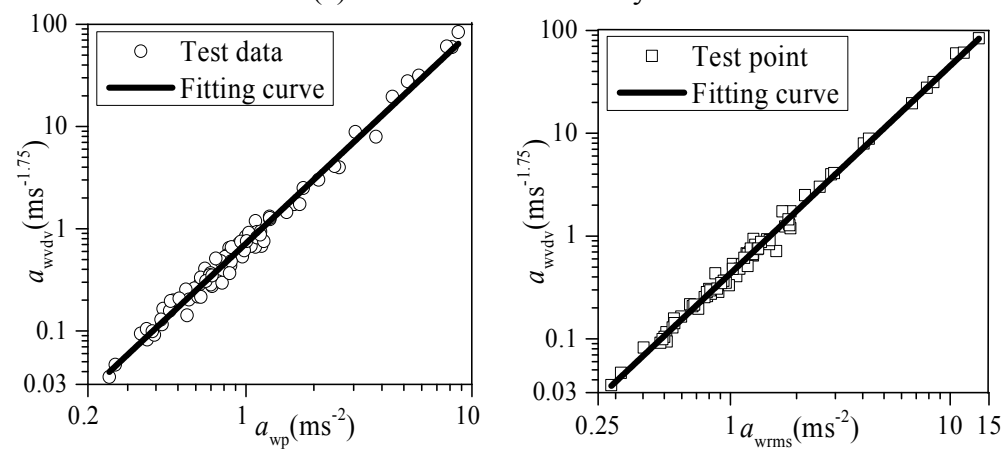

(b) Logarithmic coordinate system

Fig. $11 a_{\mathrm{wvdv}}$ plotted against $a_{\mathrm{wp}}$ and $a_{\mathrm{wrms}}$ from human induced measured data

Bearing all this in mind, when the structure was oscillated by shaking table with linear increasing excitations, the structural acceleration VDV have a linear relationship with RMS and peak value. While the structure was oscillated by crowd have rhythmic activities with linear increasing swaying frequencies, the structural acceleration VDV have a linear relationship with RMS and peak value at Logarithmic coordinate system. And what's more, crowd swaying movements can induce structure has more than $1 \mathrm{~g}$ acceleration, which can cause crowd have panic.

\section{Assessment of the experiment results}

\subsection{Acceptable VDV limits}

Not only the external excitation but also human internal vibration for the test structure in this paper, the structural acceleration curves whose characteristics vary with time, just as Fig.5 and Fig.9(a) the peaks of curve are different with times. So VDV is versatility than RMS that has been calculated to quantify human reaction to numerous types of vibration, and VDV will be used for finding the relationship with annoyance ratio in this paper.

Firstly, the questionnaires of the seated crowd occupied on the structure when it oscillated by external excitations are calculated by Eq.(3). And the scatter plots annoyance rate $R$ plotted against 
VDV that is shown in Fig.12, the values of VDV are the record curves of four accelerometers A1-A4. The filled dots, star dots, diamond dots and square dots stand for the distribution of annoyance rate of the four rows seated crowd at different vibration intensity. It can be seen that the distribution of crowd annoyance rate is relatively concentrated when the VDVs are small(lower than $0.3 \mathrm{~ms}^{-1.75}$ ). While the distribution of annoyance rate becomes larger and wider with VDVs between $0.3-1.8 \mathrm{~ms}^{-1.75}$, which indicates that crowd can adjust their perception and response to suit the structural vibration. But when the structure has excessive vibration, the distribution of annoyance rate will be concentrated again. It is also suggested that even crowd under the same vibration amplitude of structure, they have different response and perception for vibration, their annoyance rate varied at a range and obeyed a certain trend. So the upper boundary of scatters, lower boundary of scatters and mean value of scatters are fitted by a 5-rd degree polynomial formula, respectively, and shown in Eq.(10):

$$
\begin{gathered}
R_{\text {seated } 1}^{\prime}=0.0394 a_{w v d v}^{5}-0.3789 a_{w v d v}^{4}+1.2600 a_{w v d v}^{3}-1.8450 a_{w v d v}^{2}+1.4130 a_{w v d v}+0.1005 \\
R_{\text {seated } 2}^{\prime}=0.1415 a_{w v d v}^{5}-0.9076 a_{w v d v}^{4}+2.2310 a_{w v d v}^{3}-2.5450 a_{w v d v}^{2}+1.5210 a_{w v d v}+0.0654 \\
R_{\text {seated } 3}^{\prime}=0.1762 a_{w v d v}^{5}-0.9895 a_{w v d v}^{4}+2.1110 a_{w v d v}^{3}-2.0680 a_{w v d v}^{2}+1.1010 a_{w v d v}+0.1085
\end{gathered}
$$

With $R_{\text {seatedi }}^{\prime}$ is the annoyance rate of seated crowd, $a_{w v d v}$ is calculated by Eq.(1). $R_{\text {seated } 1}^{\prime}$ stands for the fitting curve of the upper boundary of scatters(dotted line); $R_{\text {seated } 2}^{\prime}$ stands for the fitting curve of the lower boundary of scatters(solid line); $R_{\text {seated } 3}^{\prime}$ stands for the fitting curve of the mean value of scatters(dot-dash line).
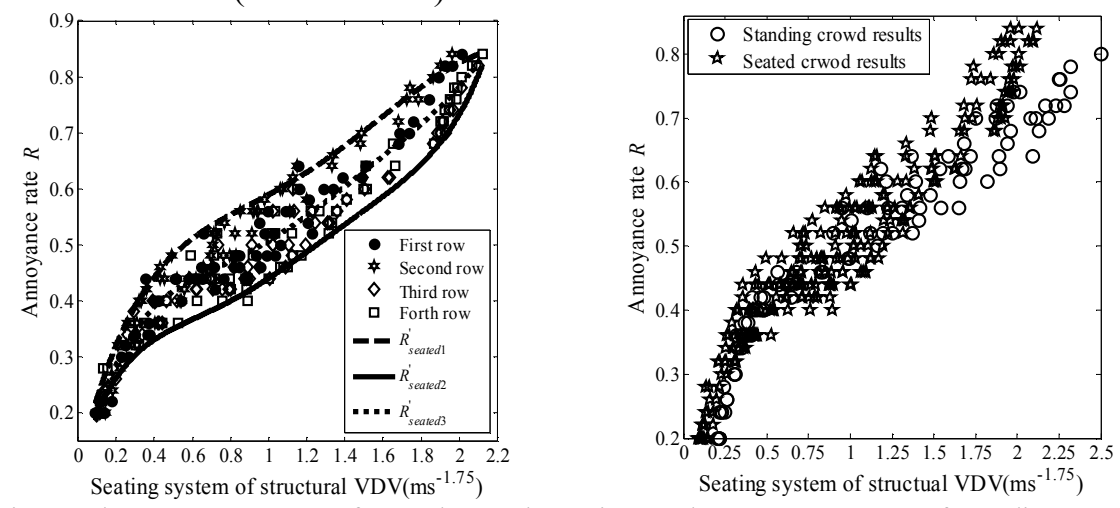

Fig. 12 The annoyance rate of seated crowds Fig. 13 The annoyance rate of standing crowds

Besides, the distribution of annoyance rate of standing crowd experiment data (circle dots) are compared with seated crowd experiment data(star dots), which is shown in Fig.13. It can be seen that the distribution of annoyance rate of standing crowd is similar to seated crowd results when structural VDV not more than $1.25 \mathrm{~ms}^{-1.75}$. But what is more interesting is that the annoyance rates of standing crowd are lower than seated crowd when structure has more larger vibration than $1.25 \mathrm{~ms}^{-1.75}$. That indicates standing crowd were more tolerant to vibration than seated crowd. Fig.13 shows crowd annoyance rate has a significant nonlinear relationship with increasing structural VDV, and when changed Cartesian coordinate system into Logarithmic coordinate system(Fig.14), it is found that there is a linear relationship between structural VDV and annoyance rate. The fitting curve is calculated by Eq.(11):

$$
\log _{10}\left(R_{\text {crowd }}^{\prime}\right)=0.42292 \log _{10}\left(a_{w v d v}\right)-0.27626
$$

With $R_{\text {crowd }}^{\prime}$ is the annoyance rate of statistic crowd at external excitation experiments. 


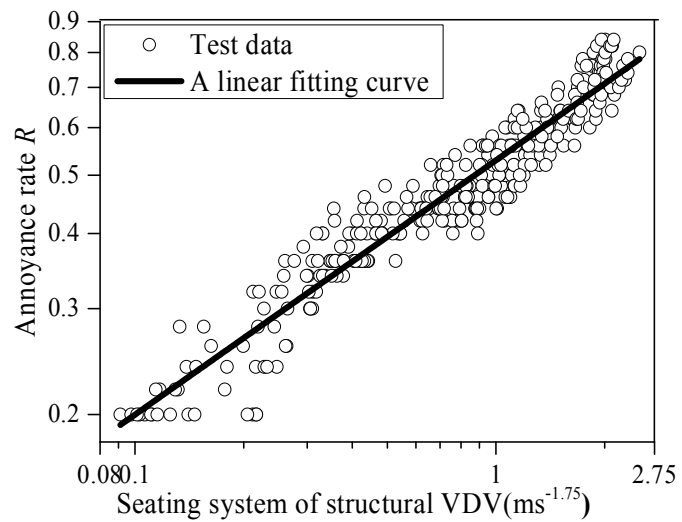

Fig. 14 The distribution of crowds annoyance rate according shaking table tests at logarithmic coordinate

Secondly, active crowd induced structure vibration experiment results are also investigated to find the relationship between annoyance rate and structural VDV. Fig.15(a) shows the distribution trend of scatters not only standing crowd(filled dots) but also seated crowd(square dots) are similar to Fig.13, It also indicates standing crowd can tolerate more strong structural vibration than seated crowd, combined with external experiment results(Fig.13), this finding consistent with Nhleko's research[13]. The two kinds of data can be fitted by a 3-rd degree polynomial formula, respectively, and shown in Eq.(12):

$$
\begin{aligned}
& R_{\text {seated }}^{\prime \prime}=0.0777 a_{w v d v}^{3}-0.4280 a_{w v d v}^{2}+0.9642 a_{w v d v}+0.0041 \\
& R_{\text {standing }}^{\prime \prime}=0.0585 a_{w v d v}^{3}-0.3224 a_{w v d v}^{2}+0.7594 a_{w v d v}+0.0430
\end{aligned}
$$

With $R_{\text {seated }}^{\prime \prime}$ is the annoyance rate of seated crowd at human induced vibration experiments; $R_{\text {standing }}^{\prime \prime}$ is the annoyance rate of standing crowd at human induced vibration experiments;

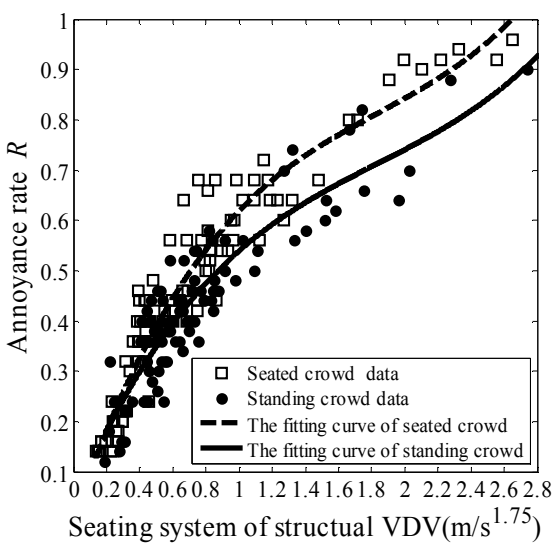

a) Cartesian coordinate system

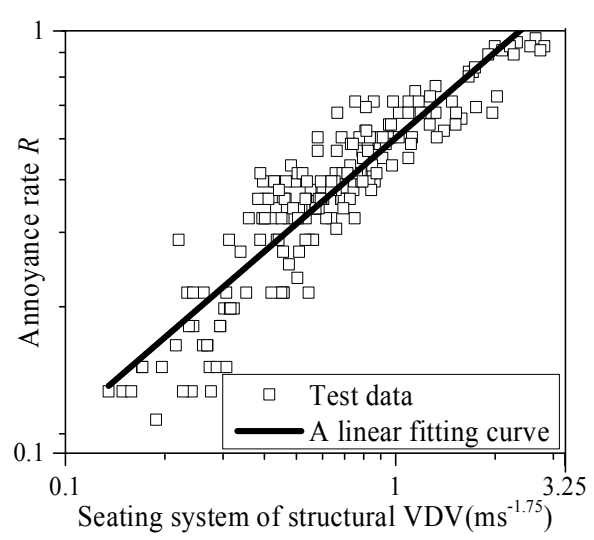

b) Logarithmic coordinate system

Fig. 15 The distribution of crowds annoyance rate at human induced structural vibration

Also, a linear relationship between structural VDV and annoyance rate at Logarithmic coordinate system is fitted by Eq.(13), and the fitting curve is shown in Fig.15(b).

$$
\log _{10}\left(R_{\text {crowd }}^{\prime \prime}\right)=0.67556 \log _{10}\left(a_{w v d v}\right)-0.25358
$$

With $R_{\text {crowd }}^{\prime \prime}$ is the annoyance rate of crowd at human induced vibration experiment.

Bearing all this in mind, both of the two experiment results can be put together as a whole to evaluate the annoyance level of vibration. So Fig.16 shows the scatters of annoyance rate with structural VDV(Fig.14 and Fig.15(b)) at Logarithmic coordinate system. It can be fitted by a linear curve with Eq.(14 a), and the formula at Cartesian coordinate system is also given in Eq.(14 b):

$$
\begin{gathered}
\log _{10}(R)=0.49118 \log _{10}\left(a_{w v d v}\right)-0.27607 \\
a_{w v d v}=10^{0.56205} \cdot R^{\frac{1}{0.49118}}
\end{gathered}
$$

With $R$ is the annoyance rate of crowd on temporary grandstand, and $a_{w v d v}$ is the acceleration VDV of seating system of temporary grandstand, its range at 0.1 to $2.8 \mathrm{~ms}^{-1.75}$. In this 
paper, when $R$ is lower than 0.4 , which indicates crowd in comfort at structure; $R$ varies at 0.4 to 0.6 means some persons in crowd have uncomfortable feelings; $R$ varies at 0.6 to 0.8 means most of them in crowd have uncomfortable feelings; and when $R$ is larger than 0.8 that shows crowd in panic. Based on this annoyance levels of vibration, the structural acceleration VDV $1.29 \mathrm{~ms}^{-1.75}$ that corresponding to $R=0.6$ as the serviceability limit, and $2.32 \mathrm{~ms}^{-1.75}$ that corresponding to $R=0.8$ as the serviceability limit of the upper boundary.

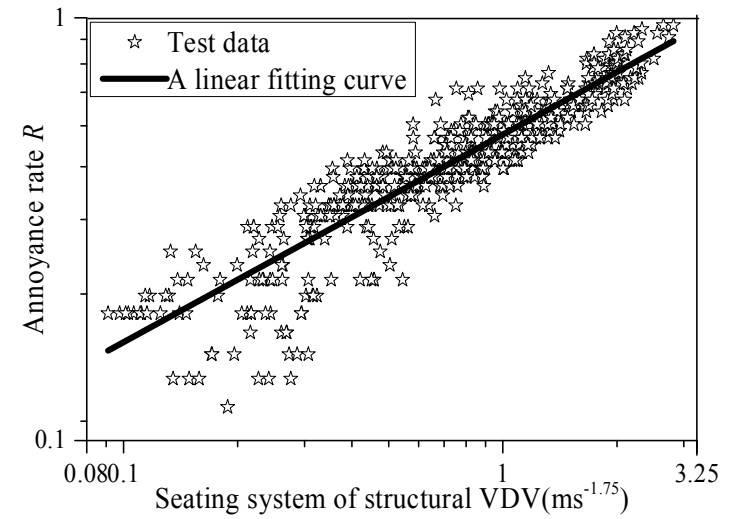

Fig. 16 The distribution of crowds annoyance rate of TDGs

\subsection{Discussion with other standards or guides and research}

The obtained comfort levels data in this paper are compared with the limits recommended in the provisions of BS6841[26], which are mainly for vibrations encountered in transportation and industrial activities. This standard used RMS as the limit and given five vibration levels which shown in Fig.17. According to the annoyance rate with structural vibrations of the experiment data in this paper, the level of comfortable corresponding to $R=0.2$ and RMS is $5.7 \% \mathrm{~g}$; the level of little uncomfortable corresponding to $R=0.4$ and $\mathrm{RMS}$ is $11.4 \% \mathrm{~g}$; the level of fairly uncomfortable corresponding to $R=0.6$ and $\mathrm{RMS}$ is $17.2 \% \mathrm{~g}$; the level of very uncomfortable corresponding to $R=0.8$ and RMS is $22.9 \% \mathrm{~g}$; and the level of extremely uncomfortable corresponding to $R>0.8$ and RMS is $28.7 \%$ g. It is found that the experiment data is slightly higher than the design criteria when the specified level under fairly uncomfortable, and the data $22.9 \% \mathrm{~g}$ appear in the specified limits when the level is very uncomfortable. This means that the limits for temporary grandstand appear upper the design criteria for public facilities such as permanent concrete structure, that is reasonable for believe temporary structures can allow to with big displacement or vibration.



Fig. 17 Comparison of test comfort data with recommendations of BS6841

The standard BS6472[31] has given some acceleration limit curves for labs, residential, office building and workshops which shown as black curves in Fig.18. Nhleko[13] used 25 times the base curve and 50 times the base curve specified in this standard as a basis and the upper boundary of acceleration limit for grandstand design(shown as two purple broken lines), respectively. In addition, NBCC2005[29] specifies serviceability acceleration limits at 4\%g-7\%g for grandstand, and IStructE2008[35] also recommends values of $3 \% \mathrm{~g}, 7.5 \% \mathrm{~g}$ and $20 \% \mathrm{~g}$ for grandstand hosting predominantly seated crowd, pop music concerts and extreme events(crowd has strong rhythmic activities), respectively. If the mean of the 'fairly uncomfortable' of comfortable obtained in this study is used to defined the serviceability limit state for temporary grandstand, the value of limit is $17.2 \% \mathrm{~g}$, which is higher than Nhleko's[13] research and NBCC2005[29] limits, but it remains in the range of IStructE2008[35] specifies limits. 


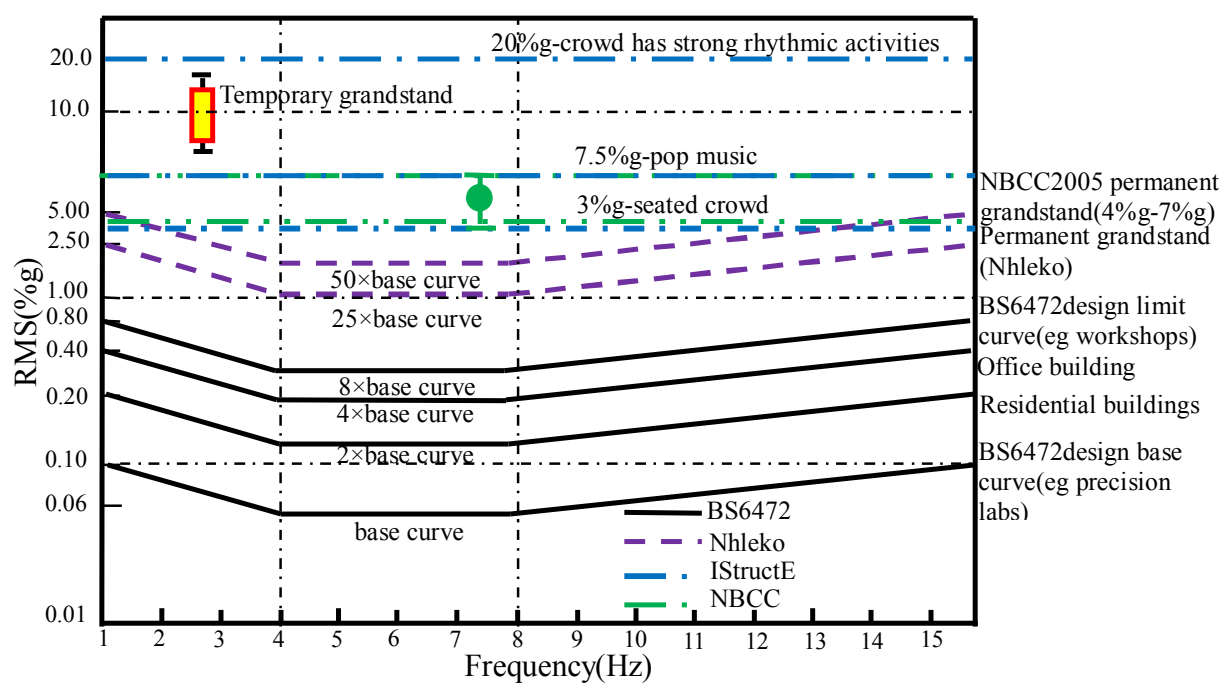

Fig.18 The design guidelines and documents of serviceability limit state for grandstand

Although the natural frequency of this test temporary grandstand is about $2.5 \mathrm{~Hz}$, according to literature [14] has investigated the natural frequency of temporary grandstand within 1.0-5.0Hz. So in order to consider the serviceability limits of other temporary grandstand with different frequencies, referring to the Figure C.2 of ISO10137(2007)[32] for structural horizontal design curve, the lateral serviceability limit curve is given in Fig. 19.

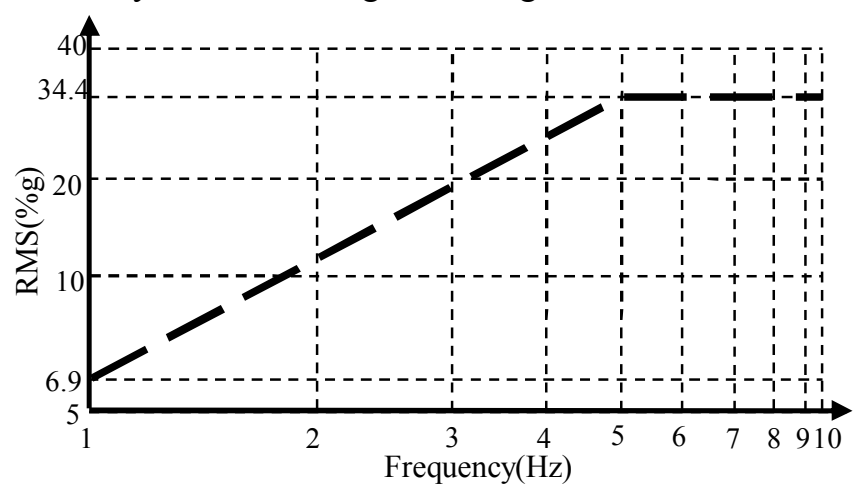

Fig. 19 The recommended limits of lateral vibration serviceability for TDGs

Table 6 Proposed ranges of VDV $\left(\mathrm{ms}^{-1.75}\right)$ for the expected human reaction

\begin{tabular}{|c|c|c|c|}
\hline \multirow[t]{2}{*}{ Comfort category } & \multicolumn{2}{|c|}{$\begin{array}{l}\text { Vertical vibration at permanent } \\
\text { grandstand }\end{array}$} & \multirow{2}{*}{$\begin{array}{c}\text { Horizontal vibration at } \\
\text { Temporary grandstand } \\
\text { This paper }\end{array}$} \\
\hline & Kasperski[3] & Setaerh $[4]$ & \\
\hline Reasonable for passive persons & $<0.66$ & $<0.50$ & $<0.57$ \\
\hline Disturbing & $0.66 \sim 2.38$ & $0.50 \sim 3.50$ & $0.57 \sim 1.29$ \\
\hline Unacceptable & $2.38 \sim 4.64$ & $3.50 \sim 6.90$ & $1.29 \sim 2.32$ \\
\hline \multirow[t]{2}{*}{ Probably causing panic } & $>4.64$ & $>6.90$ & $>2.32$ \\
\hline & & $\mathrm{BRE}[36]$ & \\
\hline Ok but may be perceptible & & $<0.6$ & \\
\hline Low probability of adverse comment & & $0.6 \sim 1.2$ & \\
\hline Adverse comment possible & & $1.2 \sim 2.4$ & \\
\hline Adverse comment probable & & $2.4 \sim 4.8$ & \\
\hline Unacceptable & & $>4.8$ & \\
\hline
\end{tabular}

When the VDV as serviceability limit, the guide BRE[36] based on the standard BS6841[26] and BS6472[31] given the limit with human perception of vibration, and Setaerh[4] based on Kasperski's[3] experiment results also gives the limits. These acceleration limits can be compared with limits investigated by this paper, which are shown in Table 6. It is noticeable that the published standards and literatures have given the limits for permanent grandstand, and the structure was induced by vertical vibration. So the serviceability limits are different from the results in this paper. It may be possible that the vibration direction and more flexible temporary grandstand have larger effects on crowd reactions than they occupied at stiffness permanent grandstand when subjected to excitations in vertical vibration. Obviously, more research is needed to investigate different and bigger temporary grandstands with different crowds, along with better 
identification of human reactions.

\section{Conclusion}

This paper addresses the annoyance levels of lateral vibration on temporary grandstand. A temporary grandstand occupied 20 participants was oscillated by a shaking table with a series random waves and induced by crowd with rhythmic swaying activities, meanwhile the vibration questionnaires of participants are obtained. Occupant comfort was evaluated by annoyance rate method and assessment by the RMS and VDV of structure. It was found that crowd annoyance rate is not a linear relationship with vibration, but indicated crowd can adjust their reaction for comfort when they under a certain range of vibration intensity. It is also indicated that standing crowd were more tolerant to vibration than seated crowd. The serviceability limit of $1.29 \mathrm{~ms}^{-1.75}$ $(17.2 \% \mathrm{~g})$ and the upper boundary of $2.32 \mathrm{~ms}^{-1.75}(22.9 \% \mathrm{~g})$ suggested by VDV (RMS) are obtained. It may be useful for analyzing the vibration serviceability of temporary grandstand.

\section{Acknowledgement}

We gratefully acknowledge the financial support provide by the National Science and Technology Support Project (NTSF) grant reference 2014BAK14B05 (Building and Applying the Large Safety Temporary Performance Platform).

\section{References}

[1] H. Bachmann. Vibrations of building structures caused by human activities, case study of a gymnasium. National Research Council of Canada, Ottawa, Ont., Technical Translation 2077, 1984.

[2] P. Dallard, A. Fitzpatrick, A. Flint, et al. London millennium bridge: pedestrian- induced lateral vibration. ASCE, Journal of Bridge Engineering,6(6)(2001)412-417.

[3] M. Kasperski Actual Problems with Stand Structures due to Spectator Induced Vibrations. Proceedings of the 3rd European Conference on Structural Dynamics: EURODYN 96, Florence, Italy. Rotterdam: Balkema, 1(1996)455-461.

[4] M. Setareh Evaluation and assessment of vibrations owning to human activity. Structures and Buildings, 165(SB5)(2012)219-230.

[5] Interim guidance on assessment and design. Dynamic performance requirements for permanent grandstands subject to crowd action. The Institution of Structural Engineers, 2001.

[6] K. Cherry A look at Introspection Wundt's Experimental Technique. https://www.verywell mind.com/what-is-introspection-2795252. 2018(Updated March 15 2018)

[7] J. P. Guidford. Psychometric methods, McGraw-Hill, New York.1954.

[8] H. Reiher, F. J. Mister. Die empfindlichkeit des menschen gegen erschutterungen(The Effect of Vibrations on People). Forschung auf dem Gebiete des Ingenieurwesens 2. Jahrang der Zeitschrift Technische Mechanik und Thermodynamik, (Research in the Areas of Engineering 2nd Year of the Journal of Applied Mechanics and Thermodynamics) Berlin. 2(11)(1931)381-386.

[9] F. Khan, R. Parmelee. Service Criteria for Tall Buildings for Wind Loading. Proceedings of the 3rd International Conference on Wind Effects on Buildings and Structures. Tokyo, Japan, 1971.

[10] P. Chen, I. L. Robertson. Human Perception Thresholds of Horizontal Motion. Journal of the Structural Division, Proceedings of the American Society of Civil Engineers, 98(ST8)(1972)1681-1695.

[11] J. F. Wiss, M. Parmelee. Human Perception of Transient Vibrations. Journal of the Structural Division, Proceedings of the American Society of Civil Engineers, 100(ST4)(1974)773-787.

[12] G.G.Browning. Human perception of vibrations due to synchronised crowd loading in grandstands. The University of Bath, UK, 2011.

[13] S Nhleko. Human-induced lateral excitation of public assembly structures[D]. The University of Oxford, 2011.

[14] B. R. Ellis, T. Ji, J. D. Littler. The response of grandstands to dynamic crowd loads. Proceedings of the Institution of Civil Engineers: Structures and Buildings, 140(4)(2000)355-365.

[15] Z.G. Song, W. L. Jin. A fuzzy-stochastic model for human response to vibrations. Journal of Basic Science and Engineering, 10(3)(2002)287-294.

[16] Z.G. Song. A new annoyance-based vibration comfort design theory on engineering structures. Zhejiang University,2003.

[17] Z.G. Song, W. L. Jin. Serviceability design of ice induced platform vibration based on ice zoning map of bohai sea-acceptable acceleration levels. The Ocean Engineering, 123(12)(2005)61-65.

[18] C. Y. Tang, T. X. Zhang, J. Q. Song. Evaluation of comfortability during vibration on basis of annoyance rate. Journal of Northeastern University(Natural Science), 27(7)(2006)802-805.

[19] C. Y. Tang, T. X. Zhang, G. Y. Zhao, et al. Annoyance rate evaluation method on ride comfort of vehicle suspension system. Journal of Mechanical Engineering, 27(2)(2014)296-303.

[20] Y. P Guo, G. Q. Song. Dynamic comfort evaluation of high-speed train based on annoyance rate model[J]. 
Journal of Northeastern University(Natural Science), 34(11)(2013)1620-1624.

[21] A. M Yuan, W. X Wu, M. Xu, et al. Study on pedestrian bridge's vibration comfort evaluation based on annoyance rate. Journal of Water Resources and Architectural Engineering, 11(4)(2013)135-140.

[22] X. Z Shen, J. Teng. Vibration serviceability assessment method for floor structures based on random walking force and annoyance rate. Journal of Vibration and Shock, 31(22)(2012)71-75,95.

[23] J. Wei, R. S Chen, J. G. Wu, et al. Appraisement of the vibration serviceability for a long-span pre-stressed floor based on annoyance rate. Zhejiang Construction, 32(1)(2015)19-23.

[24] Y. F. Huang, G. Q. Di, Y. T. Zhu, et al. Pair-wise comparison experiment on subjective annoyance rating of noise samples with different frequency spectrums but same a-weighted level. Science of The Total Environment, 69(12)(2008)1205-1211.

[25] R. H. Bakker, E. Pedersen, G. P. Van Den Berg, et al. Impact of wind turbine sound on annoyance, self-reported sleep disturbance and psychological distress. Science of The Total Environment, 425(5)(2012)42-51.

[26] BS 6841. Guide to Measurement and Evaluation of Human Exposure to Whole Body Mechanical Vibration and Repeated Shock. British Standards Institution, 1987.

[27] BS 6472-1. Guide to Evaluation of Human Exposure to Vibration in Buildings-Part 1: Vibration Sources other than Blasting. British Standards Institution. 2008.

[28] ISO 2631-1. Mechanical Vibration and Shock-Evaluation of Human Exposure to Whole-body Vibration. Part 1: General Requirement, 1997

[29] NBCC. User's Guide National Building Code of Canada 2005, Structural Commentaries (Part 4 of Division B) Commentary D. National Building Code of Canada (NBCC). 2005.

[30] BS 7085. Medical contra-indications to participation in experiments involving whole-body mechanical vibration. British Standards Institution, 1987.

[31] BS 6472. Guide to Evaluation of Human Exposure to Vibration in Buildings (1Hz to 80Hz). British Standards Institution. 1992.

[32] ISO 10137. Basis for the design of structures-Serviceability of buildings against vibration. International Organization for Standardization (ISO), 2007.

[33] M. J. Griffin. Handbook of Human Vibration. Academic Press, London, UK. 1990.

[34] B. R. Ellis, J. D. Littler. Response of cantilever grandstands to crowd loads. Part 1: serviceability evaluation. Proceedings of the Institution of Civil Engineers, Structures and Buildings, 157(4)(2004)235-241.

[35] Institution of Structural Engineers. Dynamic Performance Requirements for Permanent Grandstands Subject to Crowd Action: Recommendations for Management, Design and Assessment. London, IStructE. 2008.

[36] BRE Digest 426. The Response of Structures to Dynamic Crowd Loads, 2nd End. BRE, 2004. 